\title{
PENINGKATAN KUALITAS TIDUR LANSIA WANITA MELALUI KERUTINAN MELAKUKAN SENAM LANSIA
}

\author{
Erna Silvia Budi Anggarwati ${ }^{1}$, Kuntarti $^{2}$
}

1. Program Studi Sarjana, Fakultas Ilmu Keperawatan Universitas Indonesia, Depok 16424, Indonesia

2. Fakultas Ilmu Keperawatan Universitas Indonesia, Depok 16424, Indonesia

*E-mail: ernasba@gmail.com

\begin{abstract}
Abstrak
Kualitas tidur semakin berkurang seiring dengan bertambahnya usia manusia. Latihan fisik berupa senam lansia menjadi salah satu cara untuk meningkatkan kualitas tidur pada lansia. Penelitian ini bertujuan mengetahui hubungan antara kerutinan mengikuti senam lansia dan kualitas tidur pada lansia wanita. Desain penelitian ini adalah analitik komparatif dengan pendekatan cross sectional, melibatkan 98 lansia wanita yang mengikuti senam lansia di wilayah Kelurahan Depok Jaya, Depok yang dipilih dengan teknik cluster sampling pada komunitas senam lansia. Kerutinan dalam mengikuti senam lansia diukur dengan daftar hadir senam lansia dan kualitas tidur diukur dengan Pittsburgh Sleep Quality Index (PSQI). Data dianalisis dengan uji $t$-independen. Hasil penelitian menunjukkan ada perbedaan skor PSQI lansia wanita yang rutin mengikuti senam dengan yang tidak sebesar $2,11(p<0,001)$. Penelitian ini merekomendasikan kepada praktisi kesehatan untuk melakukan advokasi ke posbindu yang belum menerapkan kegiatan senam lansia pada wilayahnya dan mendorong para lansia untuk mengikuti senam lansia secara rutin.
\end{abstract}

Kata kunci: kerutinan, kualitas tidur, lansia wanita, Pittsburgh Sleep Quality Index, senam lansia

\begin{abstract}
Increasing the Quality of Sleep Among Women Elderly by Doing Rountine Elderly Exercise. Quality of sleep decreases along with the increase of the age of a person. Exercise is one of the ways to increase sleep quality among elderly. The purpose of this study was to examine the relationships between elderly exercise routines and sleep quality among elderly women. The design of this research was Analytic Comparative with Cross Sectional approach. The research involved 98 elderly women that undertook elderly exercise at the administrative village of Depok Jaya, Depok. The respondents were selected with cluster sampling technique in the community of elderly exercise. The routine of elderly exercise was measured by the attendance list and the sleep quality was measured by Pittsburgh Sleep Quality Index (PSQI). The data were analyzed by $t$ - independent. The results showed there is a difference in PSQI scores between elderly women who undertook routine elderly exercise and non-routine for about 2,11 (p<0,001). This research recommends the health practitioner to provide advocacy at posbindu, particularly those that has not implemented elderly exercise and to encourage the elderly to undertook routine elderly exercise.
\end{abstract}

Keywords: elderly exercise, elderly women, Pittsburgh Sleep Quality Index, routine; sleep quality.

\section{Pendahuluan}

Jumlah lanjut usia (lansia) semakin meningkat setiap tahunnya baik di dunia maupun di Indonesia. Total lansia di dunia pada tahun 2013 mengalami kenaikan sebesar $8,1 \%$ jika dibandingkan tahun 2012 (World Health Organization [WHO], 2014; World Population Ageing [WPA], 2013). Benua Asia memiliki jumlah lansia tertinggi dibandingkan benua lain, yaitu 400 juta jiwa atau sekitar setengah jumlah lansia di dunia (Kemenkes RI, 2013a). Sementara di Indonesia, pada tahun 2013 terjadi peningkatan total lansia sebesar $0,89 \%$ dibandingkan tahun 2010 (Kemenkes RI, 2013b).

Masalah pemenuhan tidur merupakan masalah yang sering terjadi pada lansia. Hasil penelitian di Iran, sebesar 86,2\% dari 390 lansia 
(199 laki-laki dan 191 perempuan) dengan rata-rata usia 60 tahun atau lebih menyatakan mengalami gangguan tidur dan lebih dari separuh lansia membutuhkan waktu kurang lebih 20 menit untuk mulai tertidur (Malakouti, Foroughan, \& Nojomi, 2009). Proses menua, yang disebabkan dan ditandai dengan perubahan anatomis dan fisiologis, menyebabkan waktu tidur efektif lansia semakin berkurang. Selain itu, kualitas tidur yang buruk lebih sering dialami oleh lansia wanita daripada lansia pria (Malakouti, et al., 2009). Hal ini menimbulkan berbagai dampak negatif, antara lain dapat merusak mood lansia, merasa lemas, tidak segar saat melakukan aktivitas, dan meningkatkan risiko jatuh karena berkurangnya tingkat konsentrasi pada lansia (Neikrug \& Ancoli-Israel, 2010).

Permasalahan tidur yang dihadapi lansia dapat dijadikan sebagai acuan untuk memberikan intervensi keperawatan yang tepat dalam mengatasi masalah terkait pemenuhan tidur. Latihan fisik terbukti dapat meningkatkan pemenuhan kebutuhan tidur pada lansia karena dapat memberikan manfaat relaksasi, memperlancar peredaran darah, dan dapat mengurangi stres (Youngsted, 2005; Sharma, Parashar, \& Sharma, 2013). Salah satu latihan fisik yang dilakukan oleh lansia di Indonesia adalah senam lansia yang biasa dilakukan di pagi hari secara teratur. Senam lansia mempunyai gerakan yang ringan, sehingga tepat untuk lansia yang kemampuan tubuhnya sudah menurun (Widianti \& Proverawati, 2010). Pelaksanaan senam lansia menjadi ukuran penting untuk mendapatkan hasil yang maksimal dalam membantu kualitas tidur lansia. Saat ini belum diketahui hubungan kerutinan mengikuti senam lansia dan kualitas tidur lansia wanita.

\section{Metode}

Penelitian ini menggunakan desain analitik komparatif dengan pendekatan cross sectional. Penelitian melibatkan 98 responden yaitu lansia wanita yang mengikuti senam lansia di Kelurahan Depok Jaya, Depok dan dipilih dengan teknik cluster sampling. Senam lansia yang dilaksanakan di komunitas adalah senam diabetes, senam jantung, senam osteoporosis, senam otak, dan senam poco-poco.

Instrumen yang digunakan dalam penelitian ini adalah Pittsburgh Sleep Quality Index (PSQI) dengan nilai cronbach's alpha 0,707, yang dikembangkan oleh Buysse, Reynolds, Monk, Berman, \& Kupfer (1989) di Universitas Pittsburgh, Amerika untuk mengukur kualitas tidur yang terdiri dari tujuh komponen, yaitu kualitas tidur subjektif, latensi tidur, durasi tidur, gangguan tidur, efisiensi tidur, penggunaan obat tidur, dan disfungsi tidur pada siang hari. Pengukuran kualitas tidur dengan menjawab 10 pertanyaan di kuesioner. Penilaian terhadap hasil dari jawaban pada kuesioner memiliki rentang skor 0-3, selanjutnya dijumlahkan dari jawaban masing-masing komponen sampai diperoleh skor total antara 0-21. Intrepretasi data kualitas tidur baik $\leq 5$, buruk $>5$ (Buysse, Reynolds, Monk, Berman, \& Kupfer, 1989).

Variabel kerutinan mengikuti senam lansia diukur menggunakan daftar hadir senam lansia dalam sebulan terakhir. Kriteria rutin mengikuti senam lansia jika frekuensi kehadiran lebih dari/sama dengan 8,1 (rerata kehadiran) pada tiga cluster yang mengadakan senam lansia sebanyak $3 \mathrm{kali} / \mathrm{minggu}$, dan kriteria rutin selanjutnya adalah jika frekuensi kehadiran lebih dari/sama dengan 7,2 (rerata kehadiran) pada dua cluster yang mengadakan senam lansia 2 kali/minggu.

Analisis data yang digunakan dalam penelitian ini adalah analisis univariat dan bivariat. Analisis univariat mengggambarkan faktor yang mempengaruhi tidur (penyakit saat ini, konsumsi obat dan substansi saat ini, lingkungan saat tidur, dan aktivitas fisik), kerutinan mengikuti senam lansia, dan kualitas tidur. Analisis bivariat pada penelitian ini menggunakan Independen t-test untuk mengetahui hubungan antara kerutinan mengikuti senam lansia dan kualitas tidur. Pada uji bivariat perbedaan kua- 
litas tidur berdasarkan faktor-faktor yang mempengaruhi tidur yaitu konsumsi substansi (kafein), lingkungan suhu dan cahaya menggunakan Uji Anova.

\section{Hasil}

Lansia wanita yang menjadi responden penelitian ini, rerata berusia $67,48 \pm 4,968$ tahun dari rentang usia 60 sampai dengan 79 tahun dan pendidikan terakhir lansia wanita sebagian besar lulusan SMA (48\%). Lebih dari separuh lansia wanita pada penelitian ini mengikuti senam lansia secara rutin $(59,2 \%)$ (Tabel 1). Lansia wanita pada penelitian ini memiliki rerata skor total PSQI adalah 7,08 $\pm 2,794$ (Tabel 2).

Lansia wanita yang tidak rutin mengikuti senam lansia memiliki rerata skor total PSQI 8,33 (2,566). Hasil tersebut lebih tinggi dibandingkan dengan lansia wanita yang rutin mengikuti senam lansia 6,22 (2,636) (Tabel 3). Pada setiap komponen kualitas tidur, kelompok lansia yang rutin mengikuti senam lansia memiliki rerata skor PSQI yang lebih rendah dibandingkan kelompok yang tidak rutin mengikuti senam lansia, yaitu komponen efisiensi tidur, latensi tidur, durasi tidur, gangguan tidur, gangguan beraktivitas, dan kualitas tidur subjektif.

Efisiensi tidur lansia wanita yang mengikuti senam lansia lebih baik yaitu $78,12 \%$ dibandingkan dengan lansia yang tidak rutin mengikuti senam lansia yaitu 70,26\%. Lansia wanita yang rutin mengikuti senam lansia membutuhkan waktu yang lebih sedikit untuk dapat tertidur (latensi tidur) yaitu sekitar 18 menit dibandingkan dengan lansia yang tidak rutin mengikuti senam lansia membutuhkan waktu sekitar 27 menit untuk dapat jatuh tertidur. Rerata durasi tidur lansia wanita adalah 4,46 $(1,29)$ jam, artinya rerata lama tidur pulas lansia selama kurang lebih 4 jam. Lansia yang rutin mengikuti senam lansia mempunyai sedikit durasi tidur yang lebih tinggi yaitu 4,58 jam (Tabel 2).

Hasil penelitian ini menunjukkan bahwa lansia wanita yang mengikuti senam lansia secara rutin memiliki skor total PSQI 2,11 poin lebih rendah daripada yang mengikuti senam, tetapi tidak rutin. Hasil analisis lebih lanjut didapatkan terdapat hubungan yang bermakna antara kerutinan mengikuti senam lansia dan kualitas tidur lansia wanita $(\mathrm{p}<0,001)$.

Tabel 1. Responden Berdasarkan Faktor yang Memengaruhi Tidur

\begin{tabular}{lcc}
\hline \multicolumn{1}{c}{ Faktor yang Memengaruhi Tidur } & Frekuensi & Persentase (\%) \\
\hline Obat & & \\
Mengkonsumsi obat & 66 & 67,3 \\
Tidak mengkonsumsi obat & 32 & 32,7 \\
Substansi & 56 & 57,1 \\
Teh & 11 & 11,2 \\
Kopi & 8 & 8,2 \\
Teh dan kopi & 23 & 23,5 \\
$\quad$ Tidak minum keduanya & & \\
Penyakit & 31 & 31,6 \\
Hipertensi & 67 & 68,4 \\
$\quad$ Ya & & \\
Tidak & 4 & 4,1 \\
Darah rendah & 94 & 95,9 \\
Ya & & 27,6 \\
Tidak & 27 & 72,4 \\
Diabetes & 71 & \\
Ya & &
\end{tabular}




\begin{tabular}{lcc}
\hline Faktor yang Memengaruhi Tidur & Frekuensi & Persentase (\%) \\
\hline Ya & 22 & 22,4 \\
Tidak & 76 & 77,6 \\
Penyakit lain & & 37,8 \\
Ya & 37 & 62,2 \\
Tidak & 61 & \\
Lingkungan: & & 16,3 \\
Cahaya & 16 & 46,9 \\
Terang & 46 & 36,7 \\
Redup & 36 & \\
Gelap & & 9,2 \\
Suhu & 9 & 78,6 \\
Hangat & 77 & 12,2 \\
Biasa & 12 & 4,1 \\
Dingin & & 95,9 \\
Suara & 4 & \\
Berisik & 94 & \\
Sepi & & \\
\hline
\end{tabular}

Tabel 2. Kerutinan Lansia Wanita Mengikuti Senam Lansia

\begin{tabular}{lcc}
\hline \multicolumn{1}{c}{$\begin{array}{c}\text { Kerutinan Mengikuti } \\
\text { Senam Lansia }\end{array}$} & Frekuensi & Persentase (\%) \\
\hline Rutin & 58 & 59,2 \\
Tidak rutin & 40 & 40,8 \\
\hline
\end{tabular}

Tabel 3. Rerata Skor PSQI (KualitasTidur) dan Komponen PSQI Berdasarkan Kerutinan Mengikuti Senam Lansia

\begin{tabular}{|c|c|c|c|c|c|}
\hline \multirow[t]{2}{*}{ Variabel } & $\begin{array}{c}\text { Senam lansia } \\
\text { rutin } \\
(\mathrm{n}=58)\end{array}$ & $\begin{array}{c}\text { Senam lansia } \\
\text { tidak rutin } \\
(n=40)\end{array}$ & $\begin{array}{c}\text { Total } \\
(\mathbf{N}=98)\end{array}$ & \multirow[t]{2}{*}{$\mathbf{t}$} & \multirow[t]{2}{*}{$\mathbf{p}$} \\
\hline & Mean \pm SD & Mean \pm SD & Mean \pm SD & & \\
\hline Skor global PSQI (0-21) & $6,22 \pm 2,636$ & $8,33 \pm 2,566$ & $7,08 \pm 2,794$ & $-3,920$ & $0,000 *$ \\
\hline Efisiensi Tidur (0-3) & $1,19 \pm 1,20$ & $1,80 \pm 1,18$ & $1,44 \pm 1,227$ & & \\
\hline Latensi Tidur (0-3) & $0,86 \pm 0,73$ & $1,18 \pm 0,84$ & $0,99 \pm 0,793$ & & \\
\hline Durasi Tidur (0-3) & $2,16 \pm 0,95$ & $2,48 \pm 0,87$ & $2,29 \pm 0,931$ & & \\
\hline Gangguan Tidur (0-3) & $1,05 \pm 0,39$ & $1,35 \pm 0,53$ & $1,17 \pm 0,477$ & & \\
\hline Penggunaan Obat Tidur (0-3) & 0 & 0 & 0 & & \\
\hline Gangguan Beraktivitas (0-3) & $0,14 \pm 0,39$ & $0,43 \pm 0,67$ & $0,26 \pm 0,543$ & & \\
\hline Kualitas Tidur Subjektif (0-3) & $0,83 \pm 0,59$ & $1,10 \pm 0,63$ & $0,94 \pm 0,623$ & & \\
\hline Efisiensi Tidur (\%) & $78,12 \pm 19,19$ & $70,26 \pm 17,71$ & $4,91 \pm 18,91$ & & \\
\hline Latensi Tidur (menit) & $18,78 \pm 21,54$ & $27,00 \pm 29,08$ & $22,13 \pm 25,08$ & & \\
\hline Durasi Tidur (jam) & $4,58 \pm 1,370$ & $4,30 \pm 1,170$ & $4,46 \pm 1,29$ & & \\
\hline
\end{tabular}

\section{Pembahasan}

Penelitian yang melibatkan lansia wanita berusia rerata $67,48 \pm 4,968$ tahun ini menunjukkan bahwa ada hubungan antara kerutinan mengikuti senam lansia dengan kualitas tidur. Senam lansia sebagai latihan fisik yang khu- sus untuk para lansia merupakan salah satu terapi non farmakologi yang direkomendasikan untuk mengatasi masalah tidur pada lansia (Youngsted, 2005). Latihan fisik yang diteliti pada penelitian ini adalah senam lansia yang terdiri dari senam jantung, senam diabetes, senam osteoporosis, senam otak, dan 
diiringi dengan senam poco-poco. Setiap senam yang dilakukan terdiri dari pemanasan, latihan inti, dan pendinginan, namun fokus masing-masing pada setiap senam yang dilakukan berbeda. Senam lansia dapat meningkatkan pemenuhan kebutuhan tidur lansia karena dapat memperlancar peredaran darah, mengurangi stres dan meningkatkan relaksasi.

Setiap komunitas senam melaksanakan senam selama $\pm 1,5$ jam, jika diukur berdasarkan rerata kehadiran, maka jumlah mengikuti senam lansia minimal pada penelitian ini adalah 3 jam seminggu. Hasil ini sejalan dengan penelitian yang dilakukan oleh American Academy of Sleep Medicine bahwa olahraga yang dilakukan pada pagi hari selama minimal 3-4 jam seminggu akan menurunkan gangguan tidur. Penurunan gangguan tidur ini dapat meningkatkan kualitas tidur lansia wanita.

Kualitas tidur lansia wanita yang tidak mengikuti senam lansia secara rutin lebih buruk daripada yang rutin mengikuti senam lansia. Hal ini juga terjadi hampir pada semua komponen PSQI, yaitu komponen efisiensi tidur, latensi tidur, durasi tidur, gangguan tidur, gangguan beraktivitas, kualitas tidur subjektif, namun tidak terjadi pada komponen penggunaan obat tidur. Pada setiap komponen terlihat kualitas tidur yang lebih buruk pada lansia wanita yang tidak mengikuti senam lansia secara rutin.

Lansia wanita yang rutin mengikuti senam lansia memiliki rerata efisiensi tidur yang lebih baik daripada lansia yang tidak rutin mengikuti senam lansia. Hal ini sesuai dengan penjelasan bahwa efisiensi tidur pada usia dewasa sekitar $80 \%$ sampai $90 \%$, dan pada lansia berkurang antara 50\% sampai 70\% (Misra \& Malow, 2008 dalam Miller, 2012).

Penelitian menyatakan bahwa efisiensi tidur akan mempengaruhi kualitas tidur lansia. Efisiensi tidur ini dipengaruhi dari perasaan kesepian, isolasi, dan emosi yang lansia miliki di masa tua ( $\mathrm{Li}$ et al., 2013). Kondisi psikologis lansia mempengaruhi kebutuhan akan istirahat yang dialami oleh lansia. Waktu saat lansia benar-benar naik ke tempat tidur untuk tidur sampai lansia tidur nyenyak (durasi tidur) akan mempengaruhi efisiensi tidur lansia.

Pada penelitian ini didapatkan waktu yang dibutuhkan lansia untuk dapat tertidur adalah $22,13 \pm 25,08$ menit setelah naik ke tempat tidur dan rerata lama tidur pulas lansia adalah $4,46 \pm 1,29 \mathrm{jam}$. Lansia wanita yang rutin mengikuti senam lansia memiliki rerata latensi tidur dan durasi tidur yang lebih baik daripada lansia yang tidak rutin mengikuti senam lansia. Latihan fisik mampu mengu-rangi latensi tidur menjadi 15 menit (Li, Fisher, \& Harmer, 2004). Hal ini disebabkan karena latihan fisik mampu meingkatkan rasa rileksasi sehingga lansia mudah untuk mengawali istirahat. Hal ini tidak berbeda jauh dengan hasil penelitian ini yang menunjukkan rerata latensi tidur pada lansia yang rutin mengikuti senam lansia membutuhkan waktu sekitar 18 menit untuk dapat jatuh tertidur.

Rerata durasi tidur lansia wanita pada penelitian ini selama 4 jam tidak sejalan dengan teori yang menyatakan bahwa kuantitas tidur lansia adalah sekitar 7 jam. Hasil penelitian ini juga tidak sejalan dengan penelitian yang dilakukan Li, et al., (2004) di Taiwan yang menunjukkan bahwa rerata durasi tidur lansia yang mendapatkan intervensi Tai Chi untuk meningkatkan kualitas tidur adalah 7,45 jam. Perbedaan ini disebab-kan karena kriteria inklusi pada penelitian Li, et al., (2004) adalah lansia dalam kondisi sehat tidak memiliki penyakit agar tidak memperburuk penyakit saat dilakukan intervensi. Hal tersebut berbeda pada penelitian ini karena lansia yang memiliki penyakit tidak masuk dalam kriteria eksklusi. Selain itu, terdapat faktor konsumsi obat yang mempengaruhi kualitas tidur lansia wanita pada penelitian ini.

Rerata skor gangguan tidur lansia wanita yang mengikuti senam lansia secara rutin lebih rendah daripada yang tidak rutin mengikuti senam 
lansia. Hasil penelitian ini sejalan dengan penelitian yang dilakukan oleh Li, et al. (2004) di Taiwan terdapat selisih rerata skor gangguan tidur 0,39 antara lansia yang mendapatkan intervensi Tai Chi selama 6 bulan dibandingkan dengan rerata skor gangguan tidur sebelum diberikan intervensi. Gangguan tidur yang paling banyak dialami oleh lansia wanita pada penelitian ini adalah harus bangun untuk ke kamar mandi, tidak dapat tertidur dalam 30 menit walaupun sudah berniat untuk tidur, terbangun pada malam atau dini hari, merasa kepanasan, dan merasa nyeri. Hal ini mungkin disebabkan karena adanya faktor konsumsi obat yang dikonsumsi lansia pada penelitian ini, seperti amlodipin. Penyebab lain karena terjadinya perubahan sistem perkemihan lansia yaitu berkurangnya kapasitas kandung kemih dan rasa panas yang dialami oleh lansia karena sudah mengalami menopause.

Rerata skor gangguan beraktivitas lansia wanita yang mengikuti senam lansia secara rutin lebih rendah daripada yang tidak rutin mengikuti senam lansia. Teori menjelaskan bahwa senam lansia mampu memperlancar peredaran darah sehingga pasokan oksigen ke otak optimal. Hal ini memberikan dampak positif bagi lansia untuk menjalani aktivitas seharihari.

Lansia wanita yang rutin mengikuti senam lansia memiliki skor kualitas tidur subjektif yang lebih kecil dibandingkan dengan yang tidak rutin yaitu dengan selisih 0,27 . Hasil penelitian yang dilakukan oleh Yang, Ho, Chen, dan Chien (2012) di Taiwan, menunjukkan bahwa latihan olahraga dapat menghasilkan selisih yang lebih besar yaitu 0,47. Perbedaan hasil penelitian ini dikarenakan jumlah responden pada penelitian yang dilakukan Yang, Ho, Chen, dan Chien (2012) di Taiwan lebih banyak yaitu 305 responden dan mendapatkan eksperimen yang dikontrol intensitas, durasi, dan frekuensi latihan fisik. Latihan fisik yang diberikan berupa endurance training, berjalan, atau Tai Chi. Sementara pada penelitian ini menggunakan pendekatan cross sectional dengan membandingkan lansia wanita yang mengikuti senam lansia secara rutin dan tidak rutin.

Hasil penelitian menunjukkan bahwa rerata total skor kualitas tidur lansia wanita pada penelitian ini 7,08 yang artinya kualitas tidur buruk. Hasil penelitian ini mendukung penelitian sebelumnya di India yang menunjukkan bahwa rerata total skor kualitas tidur lansia yang mengikuti latihan aerobik adalah \pm 8 (Sharma, Parashar, \& Sharma, 2013). Hasil penelitian lain yang dilakukan Cahyono (2012) di Semarang menunjukkan rerata total skor kualitas tidur lansia yang mendapatkan intervensi senam lansia adalah 10,58. Perubahan fungsional yang mempengaruhi tidur lansia memang memberikan pengaruh terhadap kualitas tidur lansia, namun lansia yang berhasil beradaptasi terhadap perubahan fisiologis dan menemukan cara yang tepat untuk meningkatkan kualitas tidur akan lebih mudah memelihara tidur REM dan siklus tidur yang lebih baik. Hasil penelitian menunjukkan bahwa terdapat hubungan antara kerutinan mengikuti senam lansia dan kualitas tidur lansia wanita. Latihan fisik dapat meningkatkan relaksasi sehingga meningkatkan kebutuhan akan istirahat. Senam lansia secara rutin mampu meningkatkan konsumsi energi, sekresi endorfin, dan suhu tubuh yang dapat memfasilitasi tidur dalam proses penyembuhan tubuh. Aliran darah yang lancar mampu membuat transport oksigen terutama ke otak lancar sehingga dapat mengontrol tekanan darah. Hal ini dapat meningkatkan kenyamanan lansia saat tidur. Tidur dipengaruhi oleh irama sirkadian dari detak jantung dan tekanan darah yang berasal dari penurunan saraf simpatis dan peningkatan saraf parasimpatis. Senam lansia yang dilakukan secara rutin dapat meningkatan saraf parasimpatis saat tidur, sehingga menurunkan tekanan darah dan meningkatkan kualitas tidur (Chennaoui, et al., 2014).

Peningkatan sekresi hormone endorfin dari dalam tubuh juga dapat terjadi pada lansia yang rutin mengikuti senam lansia. Hormon 
Peningkatan sekresi hormon endorfin dari dalam tubuh juga dapat terjadi pada lansia yang rutin mengikuti senam lansia. Hormon endorfin mempunyai efek seperti morfin yang dapat berfungsi untuk penghilang nyeri secara alami dan penghilang rasa stress (Cahyono, 2012). Adanya peningkatan hormon endorfin ini akan mengurangi sensasi rasa nyeri yang dialami lansia, sehingga membuat lansia wanita lebih rileks.

Manfaat lain dalam mengikuti senam lansia secara rutin yaitu sebagai pengaturan suhu tubuh saat tidur sehingga dapat meningkatkan kualitas tidur. Hal ini sejalan dengan teori yang dikemukakan oleh Chennaoui, et al. (2014), pada saat awal tidur terjadi peningkatan suhu tubuh sebesar $1,5-2,5^{\circ} \mathrm{C}$. Setelah terjadi peningkatan suhu tubuh, hipotalamus merespon dengan menurunkan suhu sebesar $0,5-1{ }^{\circ} \mathrm{C}$ selama tidur. Senam secara teratur dapat meningkatkan suhu tubuh. Peningkatan suhu tubuh dibutuhkan oleh hipotalamus untuk melakukan penurunan suhu tubuh yang lebih teratur sehingga dapat meningkatkan kualitas tidur pada saat proses pemulihan tubuh. Hal ini dapat meningkatkan waktu pada NREM tahap 3 dan 4 yang sudah sangat menurun pada lansia (Chennaoui, et al., 2014).

Senam lansia yang diikuti oleh lansia wanita memberikan kesempatan kepada mereka untuk melakukan kegiatan dan berkumpul dengan teman-teman yang memiliki rentang usia tidak berbeda jauh. Perkumpulan ini meningkatkan interaksi antar masyarakat sehingga mencegah lansia merasa kesepian. Kegiatan ini sangat bermanfaat untuk menjaga mood lansia dan mencegah lansia merasa depresi dengan masa tuanya. Hal ini dibuktikan dengan penelitian yang dilakukan Prasetya, Hamid, \& Susanti (2008) yang menunjukkan bahwa terjadi penurunan tingkat depresi pada lansia yang mendapatkan intervensi senam otak. Dengan demikian, lansia dapat menerima segala perubahan fisik, psikologis, dan sosial yang terjadi sehingga menjalani masa tuanya dengan perasaan yang baik.
Penelitian ini memberikan implikasi untuk mahasiswa keperawatan sebagai informasi bahwa faktor kerutinan mengikuti senam lansia menjadi ukuran penting dalam mempengaruhi kualitas tidur lansia wanita. Hal ini juga dapat menjadi sumber informasi bagi institusi pendidikan untuk mengembangkan metode pembelajaran agar mahasiswa lebih memahami faktor-faktor lain yang mempengaruhi kualitas tidur lansia.

\section{Kesimpulan}

Penelitian ini meneliti adanya hubungan antara kerutinan mengikuti senam lansia dan kualitas tidur lansia wanita. Berdasarkan hasil penelitian, didapatkan bahwa terdapat hubungan antara kerutinan mengikuti senam lansia dan kualitas tidur lansia wanita. Senam lansia yang dilakukan secara rutin dapat meningkatkan kualitas tidur lansia. Jadi, kerutinan mengikuti senam merupakan faktor penting yang harus diperhatikan agar mendapatkan manfaat yang optimal dalam meningkatkan kualitas tidur lansia.

Oleh karena itu, peneliti merekomendasikan kepada praktisi kesehatan untuk melakukan advokasi ke posbindu-posbindu yang belum menerapkan kegiatan senam lansia pada wilayahnya dan mendorong para lansia untuk mengikuti senam lansia secara rutin (ER, TN, $\mathrm{PN})$.

\section{Referensi}

Buysse, D.J., Reynolds, C.F., Monk, T.H., Berman, S.R., \& Kupfer, D.J. (1989). The Pittsburgh Sleep Quality Index: A new instrument for psychiatric practice and research. Psychiatry Research, 28, 193-213.

Cahyono, K. H. (2012). Pengaruh senam lansia terhadap kualitas tidur pada lansia di Desa Leyangan Kecamatan Ungaran Timur Kabupaten Semarang. Ungaran: STIKES Ngudi Waluyo. 
Chennaoui, M., Arnal, P. J., Sauvet, F., \& Léger, D. (2014). Sleep and exercise: A reciprocal issue? Sleep Medicine Reviews. Doi:10.1016 /j.smrv.2014.06.008

Kementerian Kesehatan RI. (2013a). Gambaran Kesehatan Lanjut Usia di Indonesia. Jakarta: Kemenkes RI.

Kementerian Kesehatan RI. (2013b). Profil Kesehatan Indonesia 2013. Jakarta: Kementerian Kesehatan RI.

Li, F., Fisher, K., \& Harmer, P. (2004). Tai Chi and Self-Rated Quality of Sleep and Daytime Sleepiness in Older Adults: A Randomized Controlled Trial. Journal of the American Geriatric Society, 52, 892-900.

Malakouti, S. K., Foroughan, M., \& Nojomi, M. (2009). Sleep patterns, sleep disturbances and sleepiness in retired Iranian elders.

International Journal of Geriatric Psychiatry, 1201-1208. doi:10.1002/gps.

Miller, C. A. (2012). Nursing for Wellness in Older Adults (6th Ed.). Philadelphia: Wolters Kluwer Health, Lippincott Williams \& Wilkins.

Neikrug, A. B., \& Ancoli-Israel, S. (2010). Sleep disorders in the older adult: A mini-review.
Gerontology, 56 (2), 181-189. Doi:10.1159/00 0236900 .

Prasetya, A. S, Hamid, A. Y., \& Susanti, H. (2010). Penurunan tingkat depresi klien lansia dengan terapi kognitif dan senam latih otak. Jurnal Keperawatan Indonesia, 13 (1), 42-48.

Sharma, S., Parashar, D., \& Sharma, S. (2013). Effect of Resistance Training Over Aerobic Exercise in Improving Quality of Sleep in Older Adults. Indian Journal of Phystotherapy \& Occupational Therapy, 7 (4), 197-202.

Widianti, A.T. \& Proverawati, A. (2010). Senam Kesehatan. Yogyakarta: Nuha Medika.

World Health Organization. (2014). World Health Statistics 2014. New York: United Nations.

World Population Ageing. (2013). World Population Ageing 2013. New York: United Nations.

Yang, P.Y., Ho, K.H., Chen, H.C., \& Chien, M.Y. (2012). Exercise training improves sleep quality in middle-aged and older adults with sleep problems: a systematic review. Journal of Physiotherapy, 58 (3), 157-63. Doi:10. 1016/S1836-9553(12)70106-6.

Youngstedt, S.D. (2005). Effects of exercise on sleep. Clinical Journal of Sport Medicine, 24: $355-36$ 